\title{
VETERINARY
}

\section{Epizootological aspects of rabies of animals in Khmelnytskyi region}

\author{
T. M. Karchevska ${ }^{1}$, T. M. Suprovych ${ }^{2}$
}

Podilsky State Agrarian Technical University, Kamianets-Podilskyi, Ukraine
Corresponding author. E-mail: ${ }^{1}$ ktmkp2015@ gmail.com, ${ }^{2}$ suprovycht@ gmail.com

Paper received 21.08.18; Accepted for publication 28.08.18.

https://doi.org/10.31174/SEND-NT2018-179VI21-19

\begin{abstract}
There exists a permanently disturbing epizootic situation regarding animal rabies in Khmelnitskyi region. The dynamics of the disease for 2013-2017 has been analyzed and the significance of different species of animals in the preservation and distribution of the rabies agent in the territory of Khmelnitskyi region has been studied. It has been established that the main carrier and source of the rabies is red fox, which accounts for $41.3 \%$ of the total number of rabies cases in animals. It has been established that the population of red foxes in the region is growing over the years and in 2017 its number for 1 thousand hectares of hunting grounds exceeded the norm twofold.
\end{abstract}

Keywords: rabies, epizootic situation, species structure, red fox, population density

Introduction. For many thousands of years, rabies remains an incurable and deadly disease. The disease is registered on all continents, and according to statistics, rabies is registered in 113 countries of the world, where up to 15 million people are affected each year and receive referral for treatment on suspicion of infectious rabies, and only 4.4 million receive treatment. In the absence of timely treatment, up to 5.5 million people and more than 1 million animals on the planet die from this disease annually. Direct losses from rabies are equal about 4 billion euros. Ukraine now ranks 3rd in Europe concerning the spread of rabies among wild and domestic animals after the Russian Federation and Belarus [8]. Active foci of the natural type of this particularly dangerous infection exist practically throughout the territory of Ukraine.

Currently, the control of the number of stray animals is of paramount importance in terms of ensuring the protection of the population from infectious diseases.

Dogs, cats, and wild carnivores need accination against rabies, it is most urgent now that the incidence of the disease is increasing. In recent years, the epizootic situation regarding rabies in Ukraine remains quite tense.

Abrief overview of publications on the topic. Based on epizootic data, in all cases, domestic animals are infected with rabies from wild predators, and foxes are found to be the main source of the infectious agent in our time, their proportion sometimes exceeds $50 \%$ of all diseased animals $[6,7]$. The ability of the fox population to reproduce after hunting normalizes the density of the population of foxes in nature only for a short time. It was established that when the population of foxes in nature is reducing by $40 \%$ due to hunting complete restoration of the livestock occurs in 2 years. In spite of the positive antiepizootic measures carried out by the local authorities, there is still an abundance of stray animals (mostly dogs and cats) that live in the courtyards of homes, kindergartens, schools, shops, bus stations, etc. [5, p.49]. In addition to foxes, other wild animals are actively involved in the sustainability of the epizootic process. Thus, during 2004- 2014 in the Chernihiv region 131 cases of diseases were recorded in rabbits, raccoon dogs, badgers, ferrets, wolves, beavers, and wild boars. In addition, one case of rabies in the roe deer and muskrat was laboratory confirmed [3, p.7]. To date, there has been a tendency towards an increased number of outbreaks of rabies among domestic carnivores, namely cats, which testifies to the lack of regulation of their numbers in cities and rural areas, as well as the absence of planned vaccinations in this species of animals. The shift of the rabies epicenter from the eastern and north-eastern regions to the northwestern region of Ukraine is established [2] .

It is known that the key to the fight against rabies is to create sustainable immune protection of animals as the only effective means to reduce morbidity. Over the past decades, 24 European countries have been implementing ORVs of wild carnivores, and it has been established that the implementation of national ORV programs in more than 20 countries has radically changed the epizootic situation of rabies in Europe [4].

Rabies in Khmelnytskyi region is a rather complicated problem. Eradication of the disease is problematic because of its natural focality. The presence of potential foci of the virus in nature, a large area, the peculiarities of the geographical spread of rabies and the conditions of livestock breeding complicate the fight against the disease [1, p.17]. V.G. Achilov and V.V. Nedosekov have carried out an epizootic analysis of the situation with regard to rabies in Khmelnitskyi region from 1958 to 2007 and it was established that all the administrative districts of the region are affected by the disease, and in the last decade investigated by them (19982007) the number of sick animals was maximumand amounted to 843 cases. In the structure of morbidity of animals, according to the authors, the leading role is played by foxes $(42,34 \%)$, cats $(17,95 \%), \operatorname{dogs}(16,98 \%)$, and cattle $(15,05 \%)$ [1].

Objective. The purpose of our research was to study the current epizootic situation regarding animal rabies in Khmelnytskyi region in the framework of the last 5 years (2013-2017) and the current structure of the disease by animal species.

Materials and methods. The materials of the research were: statistics of the Main Directorate of the State Consumer Protection Service in/for Khmelnytskyi region, Khmelnytsky Regional Department of Forestry and Hunting, epizootiological survey reports from the affected areas, reports of state institutions of veterinary medicine for Khmelnytskyi region and Khmelnytskyi district, supporting documents and primary veterinary record materials. Statistical methods baed on retrospective epidemiological analysis and expert assessments were used in our studies,

Results and discussion. According to the results of the analysis of the epizootic situation, it has been established that for 2013-2017, 337 cases of rabies in different species of animals were recorded in Khmelnytskyi region.

As can be seen from the dynamics of the species structure (Table 1), the largest number of cases of rabies was recorded in 2015 (85), somewhat lower - in 2013 (75) and 2017 (67). 
The species structure of the disease was registered in 11 species of animals, most of the cases of rabies is foxes - 139 cases $(41.3 \%)$, somewhat fewer dogs - 70 cases $(20.7 \%)$, cattle - 68 cases $(20.2 \%)$, cats - 45 cases $(13.4 \%)$, small cattle - 4 cases $(1.2 \%)$, horses - 1 case $(0.3 \%)$, badgers - 2 cases $(0.6 \%)$, martens - 3 cases $(0,9 \%)$, other species of animals (skunks, pet rats, raccoons) - 5 cases $(1,4 \%)$. The number of rabies in bovine animals is almost the same as that of rabies among dogs and exceeds the number of cases of rabies in cats by $6.8 \%$, which is a rather disturbing indicator.

Table 1. Dynamics of the species structure of the rabies affected animals for 2013-2017

\begin{tabular}{|c|c|c|c|c|c|c|c|c|c|c|c|c|}
\hline \multirow{2}{*}{$\begin{array}{l}\text { Species of } \\
\text { animals }\end{array}$} & \multicolumn{2}{|c|}{2013} & \multicolumn{2}{|c|}{2014} & \multicolumn{2}{|c|}{2015} & \multicolumn{2}{|c|}{2016} & \multicolumn{2}{|c|}{2017} & \multicolumn{2}{|c|}{ Total } \\
\hline & Inci-dence & $\%$ & Inci-dence & $\%$ & Inci-dence & $\%$ & Inci-dence & $\%$ & Inci-dence & $\%$ & Inci-dence & $\%$ \\
\hline Cattle & 19 & 25,4 & 10 & 18,2 & 12 & 14,1 & 12 & 21,8 & 15 & 22,4 & 68 & 20,2 \\
\hline Small cattle & 0 & 0 & 1 & 1,8 & 2 & 2,4 & 0 & 0 & 1 & 1,5 & 4 & 1,2 \\
\hline Dogs & 15 & 20 & 16 & 29,1 & 19 & 22,3 & 7 & 12,8 & 13 & 19,4 & 70 & 20,7 \\
\hline Cats & 10 & 13,3 & 11 & 20 & 12 & 14,1 & 5 & 9 & 7 & 10,5 & 45 & 13,4 \\
\hline Foxes & 28 & 37,3 & 16 & 29,1 & 37 & 43,5 & 30 & 54,6 & 28 & 41,7 & 139 & 41,3 \\
\hline Horses & 0 & 0 & 0 & 0 & 1 & 1,2 & 0 & 0 & 0 & 0 & 1 & 0,3 \\
\hline Badgers & 0 & 0 & 0 & 0 & 1 & 1,2 & 0 & 0 & 1 & 1,5 & 2 & 0,6 \\
\hline Martens & 2 & 2,7 & 1 & 1,8 & 0 & 0 & 0 & 0 & 0 & 0 & 3 & 0,9 \\
\hline other & 1 & 1,3 & 0 & 0 & 1 & 1,2 & 1 & 1,8 & 2 & 3 & 5 & 1,4 \\
\hline Total & 75 & 100 & 55 & 100 & 85 & 100 & 55 & 100 & 67 & 100 & 337 & 100 \\
\hline
\end{tabular}

It is noteworthy that in 2016 the virological department of the Khmelnytskyi Regional State Laboratory of Veterinary Medicine examined 528 material samples and received 55 positive results, in 2017551 material samples were investigated and 67 positive results obtained. Comparing the epizootic situation in the region in 2017 against 2016, it should be noted that the number of cases of rabies increased by 12 , with the highest tendency towards increase in dogs (by 1,9 times). It is happening despite the fact that in 2016143.4 thousand heads of animals, and in 2017 - 304, 463 thousand (which is 2,12 times more) were vaccinated against the rabies,

During an epizootiological investigation of each case of rabies in animals during the last 5 years it was found that the cause of the disease of domestic and farm animals was their contact with the red fox, whose population is increasing. In order to bring the population of red fox to the norm during 2016 hunters of the region shot 3713 heads of foxes, in 2017 - 5385 heads, however, according to Khmelnytskyi Regional Department of Forestry and Hunting, after taxation performed in 2017, the number of foxes per 1 thousand hectares of the hunting grounds exceeded the norm twofold. If one should take into account the number of foxes with an accretion, then in May-September 2018, the density of the red fox population may amount to 3.7 animals per 1000 hectares of land. Given that with the increase in the number of foxes by more than 2 animals per 100 hectares of land, the epizootic process becomes uncontrolled and the number of rabies outbreaks increases sharply among animals, the issue of oral immunization of carnivores becomes of utmost importance, however it is practically not carried out due to significant financial costs, but, as the best practices of European states show, it can significantly improve the epizootic situation with rabies in general.
Analyzing veterinary documentation, we found that the main causes of the difficult situation with regard to rabies in dogs and cats were insufficient control of the rules of their keeping, irresponsibility of animal owners, resulting in an increase in the number of homeless animals, especially in the vicinity of cities, cottage areas, adjoining areas, etc., the unwillingness of the owners to conduct preventive vaccinations in a timely manner, failure on the part of stray animals catchers to fulfill their duties in capturing stray animals, and not bringing the population of wild carnivores, namely, red foxes, to the norm

Stray animals are a particular threat to people's lives due to rabies infections, and although some of them are caught by hunters and specialized brigades, and after sterilization and vaccination returned to the place where they were cought, this workis not yet properly conductedand controlled.

\section{Conclusions}

1. From 2013 to 2017, 337 cases of rabies in animals were registered in Khmelnytskyi region, and in 2017, compared with 2016, the situation deteriorated, despite twice the number of vaccinated animals.

2. It was established that the main carrier and source of a rabies agent in Khmelnytskyi region is red fox, which accounts for $41.3 \%$ of the totalnumberof cases of rabiesinanimals. Based on epizootic data, as a rule, in all cases, domestic animals were infectedby wild predators, mainlybyred foxes.

3. One of the reasons for the exacerbation of the epizootic situation with regard to rabies is the increase in the number of stray animals, irresponsibile attitude of the owners of domestic animals regarding timely vaccination of the latter against rabies and failure to bring population of the red fox, the main source of the disease, to norm.

\section{REFERENCES}

1. Achilov V.G., Nedosekov V.V. Characteristics of the epizootic process of rabies in Khmelnytskyi region // Veterinary Medicine of Ukraine. 2013. No 6. pp. 14-17.

2. Babkin M.V., Golovko M.A, Verzhykhovskyi O.M., Moroz D.A. Features of the epizootic process of rabies in Ukraine.// Veterinary Medicine of Ukraine.2013. No 8. pp. 7-10.

3. Golik M. O., Polupan I. M., Nedosekov V.V. Analysis of epizootic situation with rabies in Chernihiv region // Veterinary Medicine of Ukraine. 2015. No 5. pp. 5-8.

4. Drozhzhe Zh. M. Dynamics of the spread of rabies in Ukraine and Europe in 2003-2013//Veterinary biotechnology.2015. No 26. pp. 7076.5 .

5. Kurtiak B. M., Voloshyn R. V., Stronskyi Y. S. et al. The risks of the rabies manifestation can be minimized: Veterinary Medicine: Interdepartmental thematic scientific collection. No 103, Kharkiv, 2017. pp. 49-52.

6. Levkivskyi D.M., Levkivska N.D., Storchak Y.G., Gutyi B.V. Epizootological monitoring of animal rabies in Lviv region for 20142016, analysis of anti-rabies measures. Scientific Herald . S.Z. Gzhytskyi Lviv National University of Veterinary Medicine and Biotechnology, 2016, vol. 18, No 3 (71). pp.50-53.

7. Trach Y.A. Problems of rabies in the Carpathian region have remained // Health of animals and medicines. 2014. No 5. pp. 16-17.

8. Once more about the rabies. URL: http://oblvet.org.ua/novini/scheraz-pro-skaz (date of appeal 3.07.2018). 